\title{
LA FORMACIÓN DE VALORES EN LA EDUCACIÓN
}

SylviaSchmelkes*

\section{Los valores son asunto de la educación}

\section{La formación valoral aparece como} una clara exigencia de la sociedad al sistema educativo. Adquiere diversas formulaciones según las épocas y los contextos geográficos. Algunas de las razones más representativas que se aducen para plantear la necesidad de una formación valoral o ética se relacionan directamente con la temática de esta publicación, y en concreto con la perplejidad humana ante los rápidos cambios de la sociedad global. Son, entre otras, las siguientes:

- En términos generales, se ubica la presencia de un fenómeno de cambio de valores a nivel mundial. Los analistas que participan de esta opinión señalan el hecho de que los valores anteriores se están derrumbando y todavía no se han construido nuevos valores, o éstos son aún más individualistas. Esta situación afecta de manera especial a la población joven. Algunas de las circunstancias de ésta que se podría denominar "crisis" valoral son: la influencia debilitadora de la televisión; el cam-

* CINVESTAV-IPN. 


\section{SYLVIA SCHMELKES}

bio de la estructura familiar; el rompimiento de las relaciones entre la escuela y la comunidad.

- Hay una preocupación generalizada por los nuevos problemas éticos que surgen debido al desarrollo de la ciencia y la tecnología (la bioética, la geoética, por ejemplo). Ello debiera encontrarse incorporado en la educación, de manera que tanto los niños como los adultos sean informados de los nuevos descubrimientos y tengan también la oportunidad de considerar las consecuencias de estos desarrollos desde un punto de vista ético. Ambos aspectos tiene que ver con la calidad de vida actual e inclusive con el futuro de la humanidad. ${ }^{2}$

- Conforme las sociedades se van haciendo cada vez más internacionales y multiculturales, es necesario desarrollar formas para que esta diversidad se convierta en una fuente de riqueza en lugar de una fuente de tensión y conflicto. El respeto universal a los demás, especialmente ahí donde existe diversidad cultural, debe incorporarse a la actividad educativa de todo niño y adulto. ${ }^{3}$

- Se considera que la educación es un arma poderosa para luchar contra la discriminación sexual, racial y religiosa que sigue existiendo de facto en nuestras sociedades, la que a su vez es causa de serios conflictos en diversas partes del mundo. ${ }^{4}$ Las actitudes de intolerancia, la xenofobia y el racismo han

'Hugh Sockett, "The Moral Aspects of the Curriculum", en Philip W. Jackson, ed., Handbook of Research on Curriculum, 1992, New York, MacMillan, p. 553.

${ }^{2}$ Kaisa Savolainen, "Education and Human Rights: New Priorities", en Adult Education for International Understanding, Human Rights and Peace, Report of the Workshop Held at UIE, 1991, Hamburgo, UNESCO Institute for Education, p. 45.

${ }^{3}$ Ibidem, p. 45-6.

${ }^{4}$ Adult Education for International Understanding, Human Rights and Peace, Report of the Workshop Held at UIE, 1991, Hamburgo, UNESCO Institute for Education, p. 7. 
aumentado en los últimos años. Más recientemente, se constata el surgimiento de un ataque renovado a la universalidad de los derechos humanos que amenaza con destruir los esfuerzos de las últimas décadas por construir una sociedad internacional sobre la base de valores comunes. ${ }^{5}$

- Existe, se señala, una ética universal en pleno desarrollo, plasmada en la Declaración Universal de los Derechos Humanos y en las sucesivas generaciones de derechos inscritas en los Pactos (de derechos sociales y económicos, de derechos políticos y culturales) y en proceso de elaboración (como los derechos de los pueblos indígenas, el derecho a la salud ambiental, etc.). Esta ética universal debe ser conocida y respetada por todos. Es necesario explicitar en la actividad educativa los principios éticos que subyacen en los instrumentos universales de los derechos humanos.

- Un argumento fuerte y consensuado a nivel internacional, incluyendo a América Latina, es el que toma su inspiración del preámbulo de la Constitución de la UNESCO: "Puesto que las guerras nacen en las mentes de los hombres, es en las mentes de los hombres que deben erigirse baluartes de paz." Así también, se considera que las situaciones violatorias de los derechos humanos se deben a situaciones deseducativas que se gestan en las mentes de aquellos hombres que mayor responsabilidad tienen de resguardarlos, ${ }^{6}$ pero también de los individuos y de los pueblos que los toleran, lo que manifiesta nuestra pérdida de la capacidad de asombro, de crítica, de denuncia. En sintesis, se trata de una pérdida de valores. Para recuperarlos, se indica, hay que volver a las mentes y a los corazones de

5 "La Educación a los Derechos Humanos y a la Comprensión Internacional", Informe para la Cuadragésima Cuarta Sesión de la Conferencia Internacional de Educación, 1994, Ginebra, UNESCO, p. 1.

${ }^{6}$ Mosca y Pérez Aguirre, 1985, p.8. 
SYLVIA SCHMELKES

los hombres para fincar principios y valores que auguren una convivencia justa y fraternal. ${ }^{7}$

\section{La formación valoral es un asunto del sistema educativo}

Cuando se habla de formación valoral, aunque se acepta que la familia es quizás el espacio privilegiado para lograrlo - lo que se asocia con el derecho de los padres de formar valoralmente a sus hijos- prácticamente todos los planteamientos hacen referencia a la escuela y a otros niveles educativos formales. Una de las razones para esto es, desde luego, el carácter masivo de la escuela y su potencial impacto societal. Pero otra, sin duda de primordial importancia, se encuentra en el hecho de que, por lo que nos dice la investigación al respecto, los valores se desarrollan en los individuos en forma automática. Requieren de un proceso educativo intencionado y sistemático. Un proceso de esta naturaleza es necesario tanto para el logro del desarrollo cognoscitivo -que parece ser un prerequisito para que el sujeto llegue a la definición de principios morales- como del propio desarrollo de los principios morales

58 del sujeto. El desarrollo valoral, por tanto, no es algo que ocurra en su plenitud como fruto natural del proceso evolutivo del ser humano. Hay que perseguirlo explícita y sistemáticamente.

Es, por otra parte, inevitable que la escuela transmita valores y forme valoralmente. El problema es que, si la escuela no se propone explícitamente la formación valoral, simplemente simula una falsa neutralidad. ${ }^{8}$ Es necesario aceptar el hecho de que toda escuela, todo maestro, todo curriculum forma valoralmente. ${ }^{9}$ No hay tarea educativa auténtica que pueda prescindir de la dimensión axiológica. En la medida

${ }_{8}^{7}$ Alva Olvera y Barba, 1989, p. 2.

${ }^{8}$ Pedro Ravela, "Educación para la Democracia y los Derechos Humanos", en Educación y Derechos Humanos, 1988, marzo, año II, $\mathrm{n}^{\circ} 23$, p. 6.

${ }^{9}$ J. Reimer, D. P. Paolitto, R. H. Hersch, Promoting Moral Growth: From Piaget to Kohlberg, 1983, 2a., Waveland, Prospect Heights, p. 113. 
en que la formación valoral forma parte solamente del curriculum oculto, no es evaluable ni se puede pedir cuentas al respecto. Sobra hacer referencia al riesgo de adoctrinamiento que ello representa. Y esto constituye una razón más para exigirle al sistema educativo que explicite su marco valoral de referencia e indique claramente la forma como intenta desarrollarlo en sus alumnos.

Se aduce también la irrenunciable función socializadora de la escuela. ${ }^{10}$ Así, en una sociedad democrática, ¿quién forma para la democracia? La función socializadora de la escuela implica reconocimiento y valoración del pluralismo. Implica formar para participar y para ejercer el juicio crítico. Implica capacitar a los alumnos para que tengan iniciativa de formular propuestas. Implica llevar a los alumnos a niveles de complejidad creciente, de compromiso con lo que creen. Esto sobre todo es cierto si consideramos que la escuela actúa en paralelo con otros agentes socializadores, en ocasiones mucho más potentes en cuanto tales que la propia escuela: los medios de comunicación, el grupo de pares, la comunidad de referencia. ${ }^{11}$ Ante esta multiplicación de fuentes amorfas de socialización, la escuela pierde su espacio socializador, especialmente cuando no es capaz de incorporar a su interior, como objeto de análisis, de reflexión, de crítica y de decisión, a esas otras fuentes de socialización.

Se considera que si la escuela no forma valoralmente, o lo hace en forma oculta, no será capaz de desarrollar al ser humano en forma integral. Se acepta cada vez más ampliamente que es necesario atender los aspectos que constituyen, analíticamente, al ser humano: el cognoscitivo, el afectivo y el psicomotor; y que cualquier proceso educativo que desatienda alguno de estos aspectos, o que enfatice uno

${ }^{10}$ Felipe Tirado, "Los Derechos Humanos y su inserción en el proceso escolar", en G. Papadimitriou, Coord., Educación para la Paz y los Derechos Humanos, Memoria del curso y talleres 1991-1993, 1994, Aguascalientes, Instituto Cultural de Aguascalientes, Univ. Aut. de Aguascalientes, p. 146.

"Juan Carlos Tedesco, "La Gestión en la encrucijada de Nuestro Tiempo", en La Gestión pedagógica en la Escuela, 1992, Santiago, UNESCOOREALC, p. 34. 


\section{SYLVIA SCHMELKES}

por encima de los demás, provocará un desarrollo desequilibrado del ser humano. La escuela tradicionalmente ha acentuado el aspecto cognoscitivo por encima de los otros dos.

La formación valoral, entonces, no es sólo un asunto educativo, sino algo que debe corresponderle a la escuela. La razón para esto es doble: la escuela es la mejor capacitada para formar valoralmente a los alumnos - porque es la única que puede hacerlo intencionalmente. Y si la escuela no lo hace, la calidad de lo que hace la escuela deja mucho que desear.

\section{No es fácil que la escuela forme valoralmente}

Esta afirmación tiene su fundamento en las siguientes razones:

1. Una razón muy importante es el hecho de que los fundamentos teóricos de los procesos de formación en el terreno socioafectivo se han desarrollado mucho menos que los pertenecientes a los procesos formativos en el terreno cognoscitivo. Existen, por tanto, asideros menos sólidos para los planteamientos pedagógicos propios de la formación valoral. Por ello, las fronteras entre el quehacer pedagógico que forma individuos autónomos capaces de estructurar sus propios esquemas valóricos, y el quehacer pedagógico de carácter adoctrinador, no siempre son del todo claras. El temor a caer en el adoctrinamiento explica la resistencia de muchos actores a asumir responsabilidades en el campo de la formación valoral.

2. Otra razón importante es el hecho de que, en el terreno de la formación valoral, el papel del docente es clave, y los docentes en general no han recibido una educación sistemática de esta naturaleza; tampoco han sido formados para formar a sus alumnos valoralmente. Esto implica que todo proyecto de formación valoral debe comenzar por -o al menos incluir-actividades de formación docente. 
3. Una razón central es el hecho de que la formación valoral se adquiere como consecuencia de lo que se puede, en efecto, ejercitar y practicar. Esto significa que en el interior del aula como de la escuela en tanto institución, se vivan cotidianamente estilos de relación interpersonal y de toma de decisiones congruentes con los propósitos perseguidos. Sin embargo, nuestras escuelas no están organizadas para operar de manera democrática y nuestros docentes en las aulas tienden todavía, en la mayoría de los casos, a reproducir las formas centralistas y autoritarias con las que ellos fueron formados.

4. La cuarta razón tiene que ver con la distancia que media entre los desarrollos teóricos relacionados con la formación valoral -que entre otras cosas enfatizan los aspectos evolutivos del proceso-y la magnitud de las exigencias sociales que se plantean a la escuela, que hemos procurado resumir en la primera parte de esta presentación. Estas exigencias son en general demasiado ambiciosas, se plantean de manera abstracta y difícilmente pueden convertirse en objetivos evaluables.

5. La quinta razón, es que la escuela no puede por sí sola. Esto significa que la escuela tendría que desarrollar su capacidad de estrechar los vínculos con las agencias socializadoras de la comunidad con las que es posible hacerlo. Pero también implica la necesidad de que la escuela introduzca sistemáticamente lo que ocurre más ampliamente en la sociedad como objeto de análisis y como problema, a lo que conviene buscarle solución colectivamente. Nuevamente se requiere romper con un estilo de operar, tanto de la escuela como del aula, a fin de convertir las competencias o incomunicaciones en sinergias favorables entre agencias socializadoras.

Con lo anterior no queremos decir que la escuela no forme valoralmente. Como lo hemos dicho antes, es imposible que no lo haga, y seguramente lo ha venido haciendo, en gran parte, en el sentido socialmente deseado. No obstante, sí puede asegurarse que la escuela no ha 
SYLVIA SCHMELKES

sido tan eficaz como la sociedad parece haberlo esperado, y quizás tampoco tan eficaz como podría haber sido si se hubiera planteado, de manera intencionada y sistemática, formar en valores.

\section{Un planteamiento personal}

Es no sólo conveniente, sino necesario para el proceso de desarrollo de nuestro país, que México vaya construyendo la capacidad de su sistema educativo para formar valoralmente. La formación valoral de la que estoy hablando es aquella que promueve el desarrollo de la capacidad individual de formular juicios morales y de actuar en consecuencia. Este planteamiento es la antítesis misma del adoctrinamiento. Supone la capacidad de lograr en los alumnos una identificación de $-\mathrm{y}$ un claro rechazo a- todo intento de adoctrinamiento al que pudieran verse sometidos en la forma de demagogia política, de fanatismo religioso, de publicidad, o de cualquier otra manera de intentar imponer un proceso de dominación ideológico o cultural.

Sin embargo, y aunque parezca contradictorio con lo anterior, des-

62 de mi punto de vista formar valoralmente no implica una neutralidad valoral. No es posible concebir un proceso de formación valoral que no asuma un determinado marco valoral como referencia. No creo que la neutralidad valoral sea posible en el hecho educativo, y mucho menos en el hecho educativo orientado precisamente a la formación valoral. Por eso considero una exigencia que todo intento de formación valoral exponga con toda claridad su marco axiológico de referencia.

Creo que el marco valoral de referencia capaz, por un lado, de responder adecuadamente a las exigencias sociales del tipo de las planteadas en la primera parte de este trabajo y, por otro, de responder a las exigencias pedagógicas de un proceso de construcción de autonomías morales, es el de los derechos humanos fundamentales, universalmente conocidos. Detrás de estos derechos se encuentran las dos orientaciones valorales fundamentales: el respeto a la dignidad de la persona y la búsqueda continua de la justicia. 
Ahora bien, es necesario reconocer que los derechos humanos tal y como se encuentran actualmente definidos son fruto de un largo proceso histórico y, por lo mismo, constituyen una definición inacabada y perfectible de lo que es propiamente humano. Lo que existe actualmente constituye lo que como comunidad humana hemos logrado hasta la fecha. Propongo que se puede trabajar con ello desde esta perspectiva relativista e historizada de los mismos.

La aparente contradicción entre el no adoctrinamiento y la necesidad de un marco de referencia valoral explícito de quien pretende formar valoralmente se resuelve, probablemente, mediante la concepción pedagógica y didáctica de la formación valoral a la que personalmente me adhiero. Ésta consiste en propiciar, en un proceso que respete el desarrollo evolutivo del niño, una autodefinición de principios valóricos propios que se encuentre sustentado en el descubrimiento de los propuestos, pero también en la oportunidad de su crítica a partir de la fundamentación de sus propias soluciones a situaciones morales. Esta propuesta puede plantear una respuesta a la primera dificultad de la escuela, pero sin duda la más importante para formar en valores. Junto con la necesidad de vigilancia permanente que evite el riesgo de caer en la salida fácil, la moralizante, la formación valoral, parece exigir el desarrollo de un proyecto complejo, de múltiples procesos paralelos - de investigación, formación docente, desarrollo experimental, desarrollo curricular y de materiales, evaluación- a fin de poder enfrentar de manera adecuada la capacidad de nuestro sistema educativo de formar valoralmente. No es fácil. Pero en ello estriba quizás el complemento transformador de la perplejidad, a la que aludimos al principio de este ensayo, en este tema de la ética y los valores, que es precisamente la esperanza. Por eso considero que vale la pena emprender el proyecto. 